\title{
Appraisal Analysis on Thailand Advertisement
}

\author{
Linda Wijaya ${ }^{1}$, Afrida Hanum ${ }^{2}$, Nena Syaharani Syahaf $\mathrm{Nst}^{3}$ \\ ${ }^{1}$ English Applied Linguistic, Universitas Negeri Medan, Indonesia \\ E-mail: huangxiurung@gmail.com \\ ${ }^{2}$ English Applied Linguistic, Universitas negeri Medan, Indonesia \\ E-mail: afridahanummedanegmail.com \\ ${ }^{3}$ English Applied Linguistic, Universitas negeri Medan, Indonesia \\ E-mail: syaharanisyahafnstegmail.com
}

\begin{abstract}
Communication occurs when one can express his/her opinion, thought, idea on people, things and situations. Opinionrelated meanings in language are regarded as resources of evaluation or appraisal in language. Not necessarily good or bad in a moral sense, attitude accompanies the language utterance every person utters. As one kind of appraisal resources, attitude plays an important role in the expression of interpersonal meanings of language. Attitude refers to a way that you behave towards someone or in a particular situation, especially when this shows how you feel.The aims of this study are to analyze five advertisements in terms of content and to look deeply into the language employed in the discourse of advertisement as well as to find out the Appraisal elements used by Thailand advertisers especially to promote their product and reach the target. In This study, it is found that judgment and affect are appraisal element that most used in Thailand Advertisement because judgment is used to evaluate human behavior towards the product, and affect is used to evaluate the benefit or advantage in the product.
\end{abstract}

Keywords-Meaning; discourse; appraisal; advertisement

\section{INTRODUCTION}

Language is foremost a means of communication, and communication almost takes place within some sort of social context. Communication occurs when one can express his/her opinion, thought, idea on people, things and situations. Opinion-related meanings in language are regarded as resources of evaluation or appraisal in language. Evaluation is intended, in simple terms, as "the indication that something is good or bad". Not necessarily good or bad in a moral sense, attitude accompanies the language utterance every person utters. As one kind of appraisal resources, attitude plays an important role in the expression of interpersonal meanings of language. Attitude refers to a way that you behave towards someone or in a particular situation, especially when this shows how you feel. In Appraisal Framework, as is proposed by Martin and his colleagues, Attitude refers to values by which speakers pass judgments and associate emotional responses with participants and processes. Attitude, along with Engagement and Graduation, constitutes the Appraisal Framework in language.

The Appraisal Framework (Martin, 2003) is a particular approach to exploring, describing and explaining the way language is used to evaluate, to adopt stances, to construct textual personas and to manage interpersonal positioning and relationships. Thus it explores how speakers/writers pass judgments on other speakers/writers, their utterances, material objects, happenings and states of affairs, and thereby form alliances with those who share these views and distance themselves from those who do not. It explores how attitudes, judgments and emotive responses are explicitly presented in texts and how they may be more indirectly implied, presupposed or assumed. 
Besides, it explores how expressions of such attitudes and judgments are, in many instances, carefully managed so as to take into account the ever-present possibility of challenge or contradiction from those who hold differing views. In sum, Appraisal Framework is a system of interpersonal meanings. Speakers/writers use the resources of Appraisal to negotiate their social relationships, by telling their listeners/readers how they feel about things and people, in other words, what their attitudes are (Wu, 2013).

Amongst the multitude numbers of research in discourse analysis, the analysis of Appraisal Framework has been encountered. For instance, Wu (2013) has made his research about Appraisal Perspective Attitudinal Analysis of Public Service Advertising Discourse which shows that in the attitude system, affect turns to be the least presentation; implicit judgment shows less distribution than explicit judgment; and more judgment occur rather than affect and appreciation. Additionally, Krizan (2016) in his journal focuses on the judgment categories of capability and propriety as the research described concludes that there are the most frequently occurring of the judgment categories.

The researchers have come out of the idea to develop Appraisal Framework in depth in the Thailand advertisement. In one video, the researchers found that there were more criticisms or judgments and this phenomenon has triggered the researchers to analyze more data or various advertisements especially in Thailand ads to find the element of Appraisal Framework further. Moreover, the aims of this study are to analyze five advertisements in terms of content and to look deeply into the language employed in the discourse of advertisement as well as to find out the Appraisal element used by Thailand advertisers especially to promote their product and reach the target.

\section{A. Advertisement}

In today's society, advertisement plays an important role in communicating messages; it is an inherent part of our daily life. Among others, advertising contributes to the creation of opinions, the production of certain roles that viewers take up after their idols and the creation of shared knowledge. Advertisement cited in Abdelaal (2014) is not only an economic entity, but it also deals with values, attitudes and ideas shaping culture. Davidson in Vahid (2012) defines advertising as "a social language, a genre of spectator/reader experience, a technique of persuasion almost a world in its own right, with its own languages, customs and history, and one that sets the tone and pace for large parts of our lives. Furthermore, Williamson cited in Vahid (2012) states that "ads are message systems designed to organize perceptions and create structures of meaning."

\section{B. Creativity}

Just as a poem, painting or theory is an output that can be judged on creativity, these judgments can also be made about advertisements. Thus, specifying an advertisement to be a creative outcome allows us to use the previous literature base to develop a multi-dimentional definition and measure of creativity in advertising. Baron cited in Heberland (1992) represents an early approach to creativity. His focus was on identifying the personality traits that lead to creative responses among individuals. Furthermore, Jackson and Messick cited in Heberland (1992) identify four underlying dimensions : unusualness, appropriateness, transformation and condensation. Unusualness or novelty refers to uniqueness or infrequency against a norm. Appropriateness can be either external (refering to the degree to which a product fits the demands of the situation), or internal (the degree to which an output is consistent in its parts). Thus, appropriateness requires an evaluation of fit in the context for which the output was developed. These two dimensions are common to most conceptualizations of creativity.

\section{Critical Discourse Analysis (CDA) in Advertisement}

Fairclough cited in Abdelaal (2014) defines CDA as a kind of social practice where power and ideology influence and interact with one another. It can be said that discourse analysis is not only used in analyzing the language expression, but also it can be used as social context through advertisement. Without our realization, advertisement sometimes contributes as well as influences human's mind in order to purchase the product. 


\section{Appraisal}

Wu (2013) states the Appraisal Framework has grown out of the functional perspective in linguistics. Functional grammar perceives language as having three metafunctions, namely ideational, interpersonal and textual. The interpersonal metafunction is concerned with interaction between the addresser and the addressee in the discourse situation and with the addresser's attitude toward what he speaks or writes about. The appraisal model is multidimentional, incorporating 3 kinds of semantic resources. Attitude, the expression of feelings, Engagement, the sourcing of attitudes and negotioations of heteroglossic diversity and Graduation, the scaling of interpersonal force or for sharpening/blurring the focus of valuer relationship. The outline of the Appraisal Framework is presented as below.

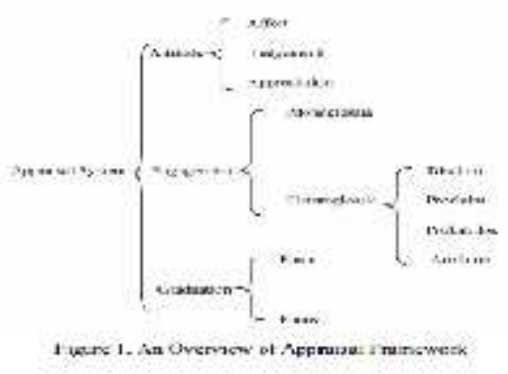

\section{METHOD}

An The data were gathered from the five advertisement videos randomly selected from Thailand advertisements. Advertising primarily concerned with beauty and health product and some electrical appliances or supplies. The data were downloaded from Youtube and transcribed into English version. In addition to the data, the researchers also attached the videos to be displayed as well. The researchers analyzed the data from the content of the advertisements. In each of these videos, the explicit and implicit attitude was identified. This research is a qualitative research.

\section{RESULTS AND DISCUSSION}

\section{A. Data Analysis}

Video 1. adv Plumbing supplies

In Thailand ads for plumbing supplies usually feature very sexy girls (judgment).
Our SANWA tap is very good. So good, in fact, that we don't need to use sex to sell it. Don't believe us? (judgment)

M : Our tap is made from high quality brass. (appreciation; thing)

Cust : I know!

M : which color, sir?

Cust : any colors, I'll take five. Quickly!

The customer will still make a purchase.

Cust : What are you laughing at?

M : It's anti-rust... hh..hhh... (judgment)

Cust : what's funny about that?

\section{Although he doesn't seem to be happy. (affect)}

F : Anything else?

Cust : Valve! ...Val... wow!!!

So, we'll go back to the old way (appreciation). Get SANWA tap and also happiness. (affect)

In this video, advertisement is used not only to promote the product, but it also considers the customer interest towards the sales person in order to have willingness to purchase the product. In term of discourse analysis, the element of appraisal which discusses about negotiating attitudes can be found in this advertisement; that is, affect, judgment and appreciation. The researchers found that judgment occurs more than affect and appreciation.

Video 2 adv Peppermint Inhaler

"Women, the biggest mystery in the Universe" (Stephen Hawking) - (judgment)

Level 1

F : Honey? What day is today? (judgment)

M : Umm... Buddhist Holy Day.

$\mathrm{F} \quad$ : (knocking the table to give sign to the man about the ring in her finger)

M : Happy Anniversary darling.

F : I love you (with excitement) (positive affect) (Judgment)

By the way, have you noticed any change?

Since the man could not answer directly, again, the female tried to remind.

$\mathrm{F} \quad$ : Anything?

M : (inside his mind, Just like photo hunt) 


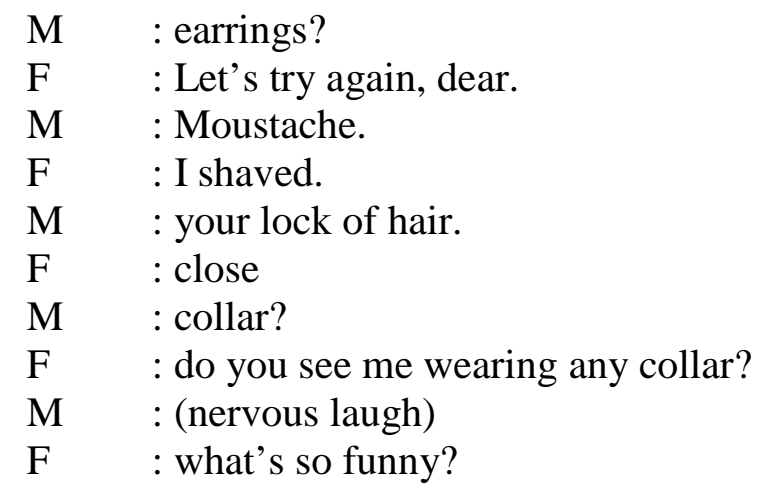

Level 2

M : I'm in deep shit. (negative affect)

F : honey, be more observant.

M : lipstick?

F : : I'll give you a hint.

M : eyebrows.

(It burns all the way to my balls) (affect)

f : Last chance, my darling.

M : cut... cut it out.

F : cut? You mean my haircut. It's new. Do you like it? (affect)

M : love it, but the old hair do was not so bad. (appreciation)

F : (disappointed with the answer) are you trying to say the old one was better? (judgment)

\section{Level 3}

M : seriously? How many more levels?

F : you like long hair like your ex's? (judgment)

M : it's all in your head, honey. It's not like that. Long hair is so overacted. (appreciation) Short hair is...

(ex-girlfriend is calling)

M : hey, Nick. I'm in the meeting. Call you back. (judgment)

(ex-girlfriend is coming)

Ex : I haven't even finished talking. Why did you hang up?

M : Why are you here?

M : Hello Nick. I'm toast! Help me! (affect)

Level 4

F : Well, do you like it short? Or long?

M : long.

F : short!

M : long.

F : choose short!

M : ok, fine. I'll go with short then.
M : Darling, I love you. (affect; judgment)

F : That's so sweet. (affect; judgment)

$\mathrm{F} \quad$ : ring? Where is...? The ring?

M : (taking out something from his pocket)

Peppermint Field Inhaler. How about opening the cap first?

After opening the cap, the male directly puts the inhaler and let the female breathe in. Cools all the way. Always keeps you cool.

In this video, the researchers found that appraisal element namely judgment is the most number occurred within the text applied by woman. At the same time, the researchers also found that affect can go together with judgment especially in the relationship between man and woman. For instance, in the sentence uttered by man Darling, I love you and the respond uttered by female That's so sweet. Actually, in this context, the female should reply I love you, too instead of That's so sweet. It tells about the feeling of affection however it is shown by giving implicit judgment within the text.

Video 3 adv Hair Mask

F : Mike, let's go. Joy is waiting.

F : (suddenly). I didn't mask my hair! Wait a minute! (judgment)

(The man is waiting)

$\mathrm{F} \quad$ : Mike. Let's go. Joy is waiting.

M : Joy is dead.

(the old fashioned way of masking hair takes too long. Use LOLAINE HAIR MASK! Faster! Use instead of hair conditioner. Your hair stays softer, longer). (judgment)

In this video, judgment is only found in analyzing the text. It can be said that Thai advertiser uses the creativity to make the product run well by criticizing woman's behavior in doing hair treatment.

Video 4 adv Slim Tea

I used to think nobody would ever understand. (affect)

(Bumping against other girls)

F : Oops, sorry.

But here, things are different.

Os : Are you new here?

F : (nod her head)

Os : Don't be shy? (affect) What class are you in? 
(showing the registration letter)

Os : Me too. Want to go together?

(introducing each other)

Activity in class while the teacher takes attendance list.

F : Everyone is nice. (affect)

We understand each other. (affect)

We put each other at ease. (affect)

F : So I feel that there is nothing to be embarrassed about. (negative affect)

In the bus shelter

Boys : You can take the seat! (judgment) Excuse me, how many months pregnant are you? (judgment)

One of friends was scolded by principal for infringing the rule of the school.

$\mathrm{P} \quad$ : Who told you?

Os : I just want to wear pretty clothes. (appreciation)

(Everybody was stunned)

$\mathrm{p}$ : What's not pretty about our school uniform?

Os : All my life, do you just want me to wear maternity clothes? (judgment)

$P \quad$ : You're being unreasonable. (judgment)

Os : Everyone has their own reason, and I have chosen mine.

After that day, everything has changed.

F : I think it's time. For me to choose my own reason.

While recalling the unpleasant moments, the female finally realized and exclaimed That's enough!

In this video, the attitude of affect is the most number occurred. As this video advertised Slim $T e a$, it showed the feeling of the fatty people. This video also contained of judgment, showing that every fat person is regarded as pregnancy. And also, regarding that this product has relation with health benefits, it tells that every woman desires of maintaining their good looking or appearance.

Video 5 adv Light bulb

In the bathroom

The light went out.

M : SON! Come and change the bulb for me!

S : Dad, which one is best to use? This old incandescent bulb. (appreciation) or the new
Sylvania bulb... which helps to reduce global warming.

D : still need to think? Huh? You're up to your neck in melted polar ice cap. And yet you still need to think? (judgment)

\section{Thai people! Let's use energy saving bulb to help reduce global warming! (appreciation)}

The last video is quite different with the other videos as it shows the appreciation and judgment to the product explicitly. The advertiser did not relate the product to the unnecessary phenomena.

TABLE I

RESULT OF VIDEO (VIDEO 1-5)

\begin{tabular}{|c|c|c|}
\hline Affect & Judgment & Appreciation \\
\hline 15 & 21 & 7 \\
\hline
\end{tabular}

\section{Percentage of The Result}

$\begin{array}{ll}\text { Affect } & =15 / 43 \times 100 \%=34,8 \% \\ \text { Judgment } & =21 / 43 \times 100 \%=48,8 \% \\ \text { Appreciation } & =7 / 43 \times 100 \%=16,2 \%\end{array}$

\section{IV.CONCLUSIONS}

Judgment refers to attitudinal evaluation in which human behavior is negatively or positively assessed by some set of social norms which include rules, conventions, social acceptability or expectation and systems of value. Affect is indicated mainly through verbs of emotion and concerned with the appraiser's emotional states. The advertisers express attitude towards some phenomenon by indicating how that phenomenon affected them emotionally and appraising something in affectual terms. Appreciation evaluates things, processes and states of affairs aesthetically. Overall, the researchers have found that Thai advertisement videos contain of judgment which does not only criticize or praises human's action, but also concerns with the social norms that affect human behavior.

Based on the findings, Thai advertisements use more judgment in the appraisal framework than affect and appreciation because the advertiser wants to show to the public that the people will feel curious and be willing to purchase the product. This is in line with the function of advertisement, that is to pursue the target. In these advertisements 
the researchers also found that Thai advertiser uses gender to stimulate the consumer's desirablitiy to use the product, instead of using children or more pictures to advertise the product as we often see in Local Advertisement.

\section{REFERENCES}

[1] Abdelaal, N. (2014). Advertisement Analysis : A Comparative Critical Study. Advances in Language and Literary Studies Vol.5 No. 6. Australia.
[2] Haberland, G. (1992). The Development of a Measure to Assess Viewers' Judgments of The Creativity of an Advertisement : A Preliminary Study. Advances in Consumer Research Vol. 19 Pages 817-825. University of Wisconsin-Madison

[3] Krizan, A. (2016). The Language of Appraisal in British Advertisements: The Construal of Attitudinal Judgment. Slovenia.

[4] Martin, J \& Rose, D. (2003). Working with Discourse: Meaning beyond The Clause. Continuum Publisher. London.

[5] Vahid, H. (2012). The Power Behind Images : Advertisement Discourse in Focus. International Journal of Linguistics Vol.4 No.4. Iran.

[6] Wu, H. (2013). Appraisal Perspective on Attitudinal : Analysis of Public Service Advertising Discourse. English Language and Literature Studies Vol.3 No.1. China. 